\title{
Complex metacarpophalangeal dislocation
}

\author{
William J. Meurer • Steven L. Kronick • \\ Mark J. Lowell • Jeffrey S. Desmond • \\ Chaitanya S. Mudgal
}

Received: 10 June 2008 / Accepted: 30 July 2008 / Published online: 20 September 2008

(C) Springer-Verlag London Ltd 2008

\begin{abstract}
A 21-year-old otherwise healthy male presented to the emergency department $24 \mathrm{~h}$ after a fall onto an outstretched hand, during the course of which he experienced hyper-extension of the right thumb and immediately noted severe pain. His range of motion had been decreased since the injury. His physical examination was notable for marked edema over the thenar eminence, along with ecchymosis and dimpling of the skin over the volar aspect of the metacarpal head. He was tender over the metacarpophalangeal (MCP) joint and had diminished range of motion. Radiographic examination of his hand revealed a dislocated MCP joint (Figs. 1 and 2). Orthopedics was consulted and took the patient to the operating room for open reduction.
\end{abstract}

Complex dislocations occur when the volar plate is ruptured and the plate becomes lodged between the base of the proximal phalanx and the metacarpal head. Historically, this type of injury has been thought to be inherently irreducible

W. J. Meurer $(\bowtie) \cdot$ S. L. Kronick $\cdot$ M. J. Lowell $\cdot$ J. S. Desmond Department of Emergency Medicine,

University of Michigan TC B1354 - SPC 5303,

1500 E. Medical Center Drive,

Ann Arbor, MI 48109-5303, USA

e-mail: wmeurer@med.umich.edu

\section{S. Mudgal}

Department of Orthopaedics - Orthopaedic Hand Service,

Massachusetts General Hospital,

Boston, MA 02114, USA by closed technique, and expeditious surgical management is advocated [1,2]. Some recommend a gentle attempt at closed reduction be performed by an experienced surgeon prior to operative management [3].

The position of the proximal phalanx parallel to the metacarpal is commonly seen on radiography. The radiographic

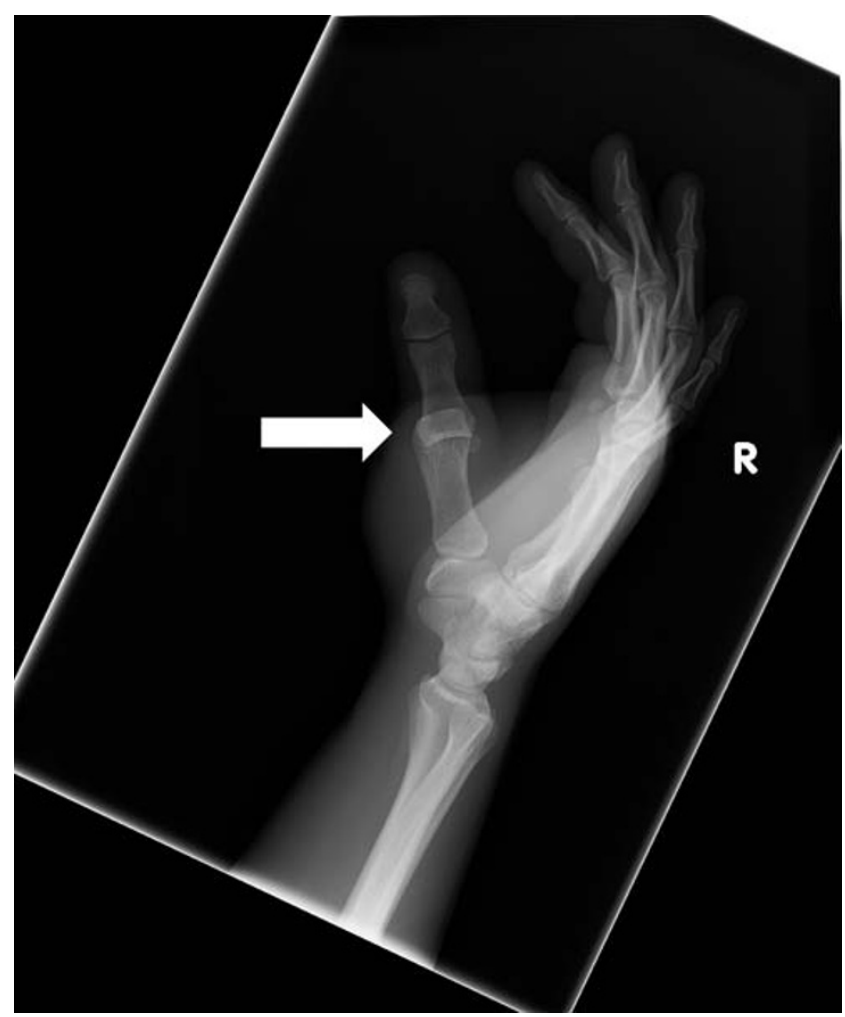

Fig. 1 Lateral plain radiograph of right hand 


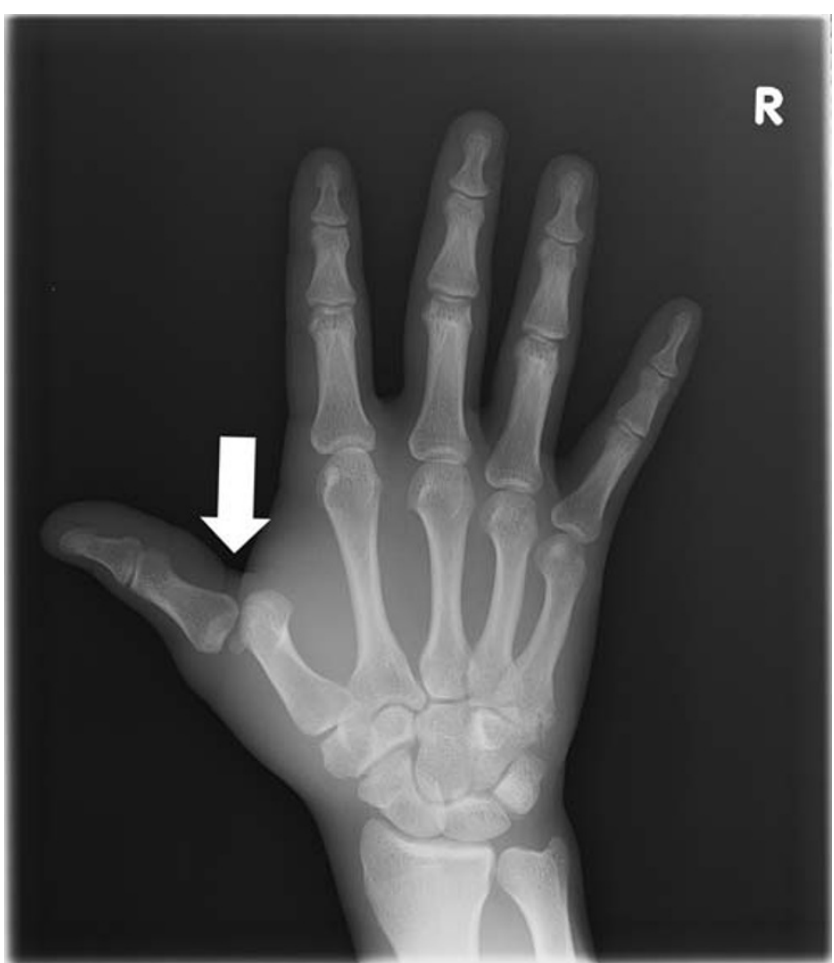

Fig. 2 AP plain radiograph of right hand finding of entrapment of one or both sesamoids within the joint space is rare, but classic for a complex MCP dislocation and seen in this case [4]. In addition, the dimpling noted over the palmar aspect of the hand is pathognomonic and was first reported by Kaplan $[5,6]$.

\section{References}

1. Farabeuf LH (1876) De la luxation du pouce en arrière. Bulletin de 1' Academie de Chirurgie 2

2. Mudgal CS, Mudgal S (2006) Volar open reduction of complex metacarpophalangeal dislocation of the index finger: a pictorial essay. Tech Hand Up Extrem Surg 10(1):31-36

3. DeLee J, Drez D, Miller MD (2003) DeLee \& Drez's orthopaedic sports medicine: principles and practice, 2nd edn. Saunders, Philadelphia, PA

4. Tavin E, Wray RC (1998) Complex dislocation of the index metacarpophalangeal joint with entrapment of a sesamoid. Ann Plast Surg 40(1):59-61

5. Kaplan EB (1957) Dorsal dislocation of the metacarpophalangeal joint of the index finger. J Bone Jt Surg 39-A(5):1081-1086. Oct

6. Boden RA, Cavale N, Fleming ANM (2006) Letter to the Editor. J Hand Surg: J Br Soc Surg Hand 31(5):576-577 